Rand, Jane ORCID:

https://orcid.org/0000-0002-2314-6761 (2016) Researching undergraduate social science research. Teaching in Higher Education, 21 (7). pp. 773-789.

Downloaded from: http://ray.yorksj.ac.uk/id/eprint/1587/

The version presented here may differ from the published version or version of record. If you intend to cite from the work you are advised to consult the publisher's version: http://www.tandfonline.com/doi/abs/10.1080/13562517.2016.1183621

Research at York St John (RaY) is an institutional repository. It supports the principles of open access by making the research outputs of the University available in digital form. Copyright of the items stored in RaY reside with the authors and/or other copyright owners. Users may access full text items free of charge, and may download a copy for private study or non-commercial research. For further reuse terms, see licence terms governing individual outputs. Institutional Repository Policy Statement

\title{
RaY
}

Research at the University of York St John

For more information please contact RaY at ray@yorksj.ac.uk 
Post-print copy of article available at:

http://www.tandfonline.com/doi/pdf/10.1080/13562517.2016.1183621

Published online: 11 May 2016

\section{Researching undergraduate social science research}

Jane Rand

Faculty of Education \& Theology, York St John University, York, UK

j.rand@yorksj.ac.uk 
Post-print copy of article available at:

http://www.tandfonline.com/doi/pdf/10.1080/13562517.2016.1183621

Published online: 11 May 2016

\section{Researching undergraduate social science research}

The experience(s) of undergraduate research students in the social sciences is under-represented in the literature in comparison to the natural sciences or science, technology, engineering and maths (STEM). The strength of STEM undergraduate research learning environments is understood to be related to an apprenticeship-mode of learning supported by more experienced (post-graduate) peers, often through ongoing research projects. Studies of undergraduate research reveal that this is not typical in the social sciences, and students report facing specific challenges to the development of their identities as researchers that include fear, intellectual confusion and emotional unsettlement. This paper examines how a social science learning environment, designed as a research study itself, fostered beginning researchers communities of practice, realised a distinct mode of apprenticing based on peers' similarly peripheral community membership, and enabled students to reframe emotional unsettlement. It argues that, effectively mediated, talk can powerfully improve undergraduate social science research students' experiences.

Keywords: undergraduate research, social science, researcher-identities, communities of practice, student involvement, emotion

\section{Introductory Discussion}

This study developed as a response to feedback from a group of third-year full-time undergraduate students in an English university who, on commencing their capstone dissertation module, reported frustration and disappointment with the summative assessment grades from an Introduction to Research Methods module in their second year of study.

This paper illuminates how beginning researchers communities of practice can improve social science undergraduate pedagogy. It explores the role of emotion(s), the 
Post-print copy of article available at:

http://www.tandfonline.com/doi/pdf/10.1080/13562517.2016.1183621

Published online: 11 May 2016

significance of talk and a unique mode of apprenticing possible in undergraduate social science research. It argues that creating opportunities for 'student involvement' (Astin 1999) can support social science undergraduates to make connections into and from their researcher-identities.

The students were studying a social science discipline: Education Studies. Research is an integral part of the programme, with modules drawing on, and examining, research in each of the three years. Similarly, positioning students as researchers is embedded within the programme - growing from tightly structured first year modules in which students gather and consider original data through interviews, through more autonomous enquiry-focussed modules in the second year (including a work-related placement), to the third-year 'capstone' dissertation (Healey and Jenkins 2009a; Todd, Smith, and Bannister 2006) - where students are required to design and pursue a self-selected programme of original research.

Informal feedback about the second year Introduction to Research Methods module had indicated that students were frustrated with, what they perceived as, low grades in proportion to the effort they expended on the module assessment (a written report of a pilot research project). They had associated increased effort because they had worked on the assessment over an extended period of time (atypically for many, starting to write during the early weeks of the twelve-week module). This is not an uncommon perception: students report feeling it is not possible to 'rush' such assessments, unlike other assessed tasks (e.g. essays) where it is possible to apply 'minimal but concentrated effort' (Todd, Bannister and Clegg 2004, 340).

My interpretation of their reported feelings and experience(s), following discussion with them about their concerns, was that they had framed the module 
Post-print copy of article available at:

http://www.tandfonline.com/doi/pdf/10.1080/13562517.2016.1183621

Published online: 11 May 2016

assessment similarly to a more tightly- and externally-defined task, rather than appreciate the nuanced systematic, iterative, reflexive characteristics of a research pilot. I posited that the transition between researching for a defined task and the 'messy, frustrating and unpredictable' (Wellington 2015, 3) nature of educational research: the 'systematic, critical and self-critical inquiry which aims to contribute to the advancement of knowledge' (Bassey 1990, 35) had been experienced as problematic. Both as a researcher myself, and also a teacher [their teacher for the year three dissertation module], I was curious about how they viewed research and, how they viewed themselves as researchers.

My teaching philosophy is underpinned by constructivism and experiential learning. Learning experiences within school and university systems can too often focus on didactic approaches and abstract examples. One, constructivist, alternative to this is to predicate learning experiences on '...interaction [that] is focussed on something that is relevant and engages in the real world', that is, learning experiences that create opportunities to learn with and from each other by drawing on practical experience(s) (Dilworth and Willis 2003, xi-xii). However, the presence (alone) of opportunities to interact with the real world would appear insufficient; in this case, students had all experienced real-world interaction in the preceding placement module but the extent to which they had been able to be reflexive - to frame this as a practical (research) experience and also consider themselves as researchers - was limited. Arguably, then, constructivist research pedagogies must create conditions whereby connections within and between research experiences, and into and from experiences as researchers are fully exploitable to and by learners. For undergraduate learning, I argue that such interaction requires a (facilitated) formal reciprocity. 
Post-print copy of article available at:

http://www.tandfonline.com/doi/pdf/10.1080/13562517.2016.1183621

Published online: 11 May 2016

Reciprocity is an exchange for mutual benefit. Students might perceive the exchange in the placement module as an opportunity to participate in a real-world education environment for the purposes of completing an assignment, broadening experience, or learning about an educational context. This perception of the exchange is geared towards achieving a (single) purpose, or using Argyris' (1976) term demonstrates a reactive, single-loop, mode of learning. A more evaluative, responsive and reflexive mode, of double-loop learning (Argyris 1976), is required for students to fully exploit the mutually beneficial relationship(s) between their research experiences and their experiences as researchers. Undergraduate reflexivity, typically, requires facilitation by those positioned as teachers (Ashwin et al. 2015).

In order to create reflexive spaces in which connections into and from researcher-identities could be constructed I was interested to learn whether acting as research participants themselves would enhance both students' experience(s) of research and their experience(s) as researchers. I chose, therefore, to frame the taught sessions of the dissertation module as a small scale research study (rather than about small scale studies as had been the case in previous years). In these sessions I would gather, and we would collaboratively analyse, data about how this particular student group viewed research and themselves as researchers. This study began with an outline research question: How does acting as a research participant impact undergraduate students' experience as researchers?

The population was a cohort of 54 students. My teaching role was two-fold: as Module Director, facilitating six three-hour (whole cohort) generalised taught sessions on designing and pursuing a self-selected programme of original research; and as 
Post-print copy of article available at:

http://www.tandfonline.com/doi/pdf/10.1080/13562517.2016.1183621

Published online: 11 May 2016

Supervisor, supporting 15 students individually with their research projects. Both roles allowed for regular contact with students, across the full academic year.

\section{Literature Review}

Much is written about undergraduate research students' experience(s) in the natural sciences or science, technology, engineering and maths (STEM) subjects (see, e.g., Linn et al. [2015]; Thiry and Laursen [2011]; Balster et al. [2010]; Lopatto [2010, 2007, 2004]; Shellito et al. [2001] and Sabatini [1997]). However there are fewer discussions around undergraduate research where contexts and datasets span, or compare, the natural and social sciences (see, e.g., Healey and Jenkins [2009a, 2009b]; Taylor and Wilding [2009]; Russell, Hancock and McCullough [2007]; Kinkead [2003]; Hathaway, Nagda and Gregerman [2002]) and far fewer examples that focus solely on the social sciences (see, e.g., Kilburn, Nind and Wiles [2014]; Todd, Bannister and Clegg [2004]; Ishiyama [2002]).

This review draws out factors that are understood to support successful undergraduate experiences associated with undertaking research (or 'discovery') and developing researcher-identities. In doing so it explores student engagement, student involvement in discovery, discovery pedagogies, and explores specifically some challenges reported by social science undergraduate students.

\section{Student Engagement}

The notion of student engagement might be considered contemporary buzzword predicated on a correlation with improved learning when students are motivated. 
Post-print copy of article available at:

http://www.tandfonline.com/doi/pdf/10.1080/13562517.2016.1183621

Published online: 11 May 2016

Learning, however, moves on its own terms:

It slips through the cracks; it creates its own cracks. Learning happens, design or no design... Those who can understand the informal yet structured, experiential yet social, character of learning - and can translate their insight into designs in the service of learning - will be the architects of our tomorrow.... Learning cannot be designed, but it can be designed for - that is facilitated or frustrated. (Wenger 1998, 225, 229 original emphasis)

Different theories of learning focus on subject matter, developmental stages, resources, and meeting the needs of individual students to achieve. Creating the necessary context for achievement (learning to do something successfully) requires the engagement of contextual stakeholders in the service of learning (that is, teachers and learners [or 'students']).

There is an argument that all student engagement should be through and about the traditional higher education values of research and enquiry (Healey and Jenkins 2009a) rather than neo-liberalist measures of 'performativity and accountability' (Zepke, 2014, 697). Research-informed teaching (Healey and Jenkins) shifts learners from a consumer role to that of producers and stakeholders within a research community. Research-informed teaching then, has the potential to re-frame the 'unquestioned academic orthodoxy' of student engagement (Zepke 2014, 698), from a model of 'being done to' to 'being done with' (Taylor and Wilding 2009, 3).

Student activity and involvement are central to research-informed teaching (Healey and Jenkins 2009b); involvement is a helpful notion because to involve is to include something as necessary [to traditional higher education values]. Student involvement has been conceptualised as 'the amount of physical and psychological energy that a student devotes to the academic experience' (Astin 1999, 518). Astin 
Post-print copy of article available at:

http://www.tandfonline.com/doi/pdf/10.1080/13562517.2016.1183621

Published online: 11 May 2016

frames involvement as connected both to (students') conceptions of effort, and also to cathexis (Freud's conceptualisation of psychological investment in objects or persons outside of the self). Central to Astin's theory is his differentiation of involvement from motivation. He argues for involvement to be recognised as contingent upon an active, behavioural, component and for motivation to be understood as a feeling that informs involvement: 'It is not so much what the individual thinks or feels, but what the individual does, how he or she behaves, that defines and identifies involvement' (Astin 1999, 519). He differentiates students' involvement in learning process[es] from their engagement with learning resources, and promotes the former over the latter.

\section{Student involvement in discovery}

Student involvement in discovery at university is considered to be transformative (Balster et al. 2010); published accounts of this, however, privilege STEM contexts in contrast to social, behavioural or economic sciences (SBES). It is understood that interaction between university staff ('faculty' in American institutions) and students can transform academic achievement and can also positively influence students' decisions to pursue post-graduate education (Hathaway, Nagda and Gregerman 2002, 1-2). Amplify that interaction to include that of mentors (typically post-graduate students, positioned as knowledgeable others, supporting students to master procedures in ongoing faculty research projects) and the transformative properties further increase.

Examples of improved academic achievement, or learning gains, litter published accounts of undergraduate research experiences. Typically associated with inprogramme/year-long initiatives (rather than summer school-style initiatives), learning gains include enhanced intellectual skills and abilities such as significant differences in 
Post-print copy of article available at:

http://www.tandfonline.com/doi/pdf/10.1080/13562517.2016.1183621

Published online: 11 May 2016

problem-solving and analysis; improved personal initiative and communications; tolerating ambiguity and obstacles; learning ethical conduct; increased depth of knowledge; integrating theory and practice; developing skills in critique; writing more effectively; developing an intrinsic motivation to learn and developing a more active approach to learning (Lopatto 2004, 2007, 2010; Bauer and Bennett 2003; Sabatini, 1997).

Concurring with Lopatto’s studies, Russell, Hancock and McCullough (2007) also argue for the benefits of year-long, integrated, initiatives. In their comparative STEM/SBES studies (total $n=6600$ ) graduates reported increased understanding, confidence and awareness as a result of undergraduate research opportunities (548); and higher aspirations [outlined later], associated more often with at least twelve months of research experience. Research experience limited to the final year of undergraduate study is considered to damage opportunities for students to identify themselves as members of a disciplinary research community (Healey and Jenkins 2009a), and so there are arguments for a progressive transitionary initiative through all undergraduate years, beginning with close supervision or structured modes of enquiry in year one, through guided enquiry, to open modes of near independence based on a broader 'socialisation' approach in year three that focuses on adopting the 'traits, habits and temperament of [scientific] researchers' (Thiry and Laursen 2011, 771; Spronken-Smith et al. 2008; Sabatini 1997).

Such research apprenticing (learning by being involved, typically, in ongoing faculty projects) might be considered traditional in the natural sciences; less so within social sciences. One reason for this may be cost effectiveness - experimental [STEM] research is conducive to laboratory-based experience(s) and therefore lends itself to 
Post-print copy of article available at:

http://www.tandfonline.com/doi/pdf/10.1080/13562517.2016.1183621

Published online: 11 May 2016

scale and quantification; more common social science approaches, such as detailed field research, do not (Todd, Bannister and Clegg 2004; Ishiyama 2002). Another reason may be associated with career trajectories; undergraduate research opportunities have been found to support career planning (Shellito et al. 2001; Sabatini 1997) and to promote career development (Hathaway, Nagda and Gregerman 2002). Russell, Hancock and McCullough (2007) identified interests in science as a career often start in childhood and, later, for SBES students in high school; whetting the appetite before university, therefore, also has significant potential.

Contingent to a research career is post-graduate education; undergraduate research experiences have been found to have the capacity to change minds, and encourage students to aspire to post-graduate education (Lopatto 2004). For those with an interest in research careers, a 'hands on' undergraduate research opportunity can underpin post-graduate aspirations; $29 \%$ of those in Russell, Hancock and McCullough's (2007) study reported a 'new expectation' of PhD study as a direct result of undergraduate research opportunities, and this was more than twice as likely when students had experienced more than 12 months' research experience. In both STEM and SBES, students are more likely to pursue post-graduate education if they have participated in undergraduate research (Hathaway, Nagda and Gregerman 2002). However there is a thorn in the side of SBES research careers: 'doctoral students in the social sciences are aware of the difficulties they face securing employment after they complete their PhD degrees' (Hathaway, Nagda and Gregerman 2002, 1). Career trajectories, therefore, are unbalanced between STEM and SBES; perhaps this reflects on, and is reflected in, the pedagogical traditions of university programmes in each. 
Post-print copy of article available at:

http://www.tandfonline.com/doi/pdf/10.1080/13562517.2016.1183621

Published online: 11 May 2016

\section{Discovery pedagogies}

Research into approaches to teaching undergraduates about research suggests that traditional, didactic, models make no contribution to the development of [workforce] skills such as communication, collaboration, critical thinking and problem solving (Kinkead 2003, 8), but involving undergraduates in research does - it results in 'connected learning' (9). A participatory pedagogy (Taylor and Wilding 2009) that

combines teaching and scholarship (rather than positions them as binary) lends itself to knowledge creation (Healey and Jenkins 2009a; Taylor and Wilding 2009; Sabatini 1997) and introduces students to an authentic 'supercomplexity' which exists in the (post-graduate and/or post-university) workforce (Barnett, 2000). Such scholarshipdriven, authentic, learning experiences might be considered 'good' by faculty, post- and under-graduate students (Shellito et al. 2001); however research into 60 empirical [STEM] studies in the last five years offers little insight into the detail of what works (Linn et al. 2015). Overwhelmingly however, findings suggest authentic opportunities to experience the practice of being a researcher are improved by the involvement of mentors (Thiry and Laursen 2011; Lopatto 2007, 2010; Kinkead 2003; Hathaway, Nagda and Gregerman 2002; Shellito et al. 2001 and Sabatini 1997).

Mentoring is considered beneficial to STEM undergraduates because of the social relationships built within and between research group members (Thiry and Laursen 2011; Lopatto 2010), where more experienced post-graduate students are positioned as knowledgeable others. Key mentor attributes include providing project(s)-guidance, professional socialisation and careers-guidance (Thiry and Laursen 2011; Shellito et al. 2001). Thiry and Laursen (2011) further conceptualise a, necessary, continuum between 
Post-print copy of article available at:

http://www.tandfonline.com/doi/pdf/10.1080/13562517.2016.1183621

Published online: 11 May 2016

STEM research supervisors and mentors. They argue that the former sometimes are not able to provide the level of support required for students to advance, where the latter can enact practices that foster students' development (Thiry and Laursen 2011, 773 emphasis added); mentors typically support students in 'mastering procedures', whilst supervisors support academic development such as analysis and conceptualisation (782). Both, they argue, are required.

\section{Learning environment(s)}

As a result of the not-insignificant research into undergraduate research initiatives one might assume that real-world research experiences should be(come) a given within undergraduate programmes, but this assumes there are no challenges. In the limited accounts of social science undergraduate research, students report challenges including fear, lacking confidence, the intellectual confusion and emotional unsettlement of developing autonomy, over-ambition, feeling stuck at the boundaries of new qualitative shifts in understanding, difficulties with gathering data (location of secondary data and recruitment of participants for primary data), the struggle of relating data and concepts to research problems, the personal organisational skills required of a dissertation, and their fluctuation '...between chaos (frustration, disorientation) and cosmos (structures they themselves constructed) when they have to make their own choices and decisions about their studies' (Silén and Uhlin 2008, 463 see also Todd, Smith and Bannister [2006]; Todd, Bannister and Clegg [2004]).

A sense of community participation is important to those new to the culture of research (Balster et al. 2010, 117). Participation is a feature, and strength, both of 
Post-print copy of article available at:

http://www.tandfonline.com/doi/pdf/10.1080/13562517.2016.1183621

Published online: 11 May 2016

apprenticeship models and research-informed teaching; it enables novices to enter into legitimate communities of practice, typically as peripheral members (Thiry and Laursen 2011). In Wenger's seminal work on communities of practice (1998) he argues that practice, rather than being an antonym for theory, can be considered as a source of meaning, as community, and as learning (49). In this sense, practice connotes knowing and doing 'in a historical and social context that gives structure and meaning to what we do’ (Wenger 1998, 47). A community of practice-based pedagogy could therefore enable the structure, and structuring, required to promote Astin's theory of student involvement for undergraduate research students because communities of practice privilege both the acquisition, and also the creation, of knowledge (Wenger 1998, 214; Tapp, 2015). But communities of practice cannot be considered separately from the identities of those who constitute them, and, paradoxically, identity is understood as relational - 'a complex matter of the social and the individual... of discourse and practice... of the rational and emotional...' (Clarke 2010, 146).

Significant for this study is that some of the challenges reported by social science undergraduate students (both in the literature, reported above, and the empirical data from this research) are framed as emotions.

In her text The Cultural Politics of Emotion, Ahmed (2014) argues that emotions shape the surfaces of collective and individual bodies, which in turn take on the shape of the contact they have with objects and others. Defining emotion as 'interiority', or looking in (Ahmed 2014, 8), she argues that the objects of emotion can become 'sticky' or saturated with affect (11), which can result in intentionally moving toward or away from the object(s) (209). Communities of practice, then, offer opportunities to mitigate 
Post-print copy of article available at:

http://www.tandfonline.com/doi/pdf/10.1080/13562517.2016.1183621

Published online: 11 May 2016

the risk that, without them, undergraduates might move away from research as a result of their emotional responses such as fear, lacking confidence and intellectual confusion.

Moreover, there is a case to be made that communities of research practice can create opportunities for the active participation and investment of physical and psychological energy necessary for undergraduate students to successfully realise the transformative potential of student involvement (Astin 1999) - to intentionally move towards their research experiences and identities as researchers. However, despite the established nature of such models in STEM undergraduate research (typically through mentored, laboratory-based, apprenticeship) no similar (scaled) models were located in the literature on social science undergraduate research.

This paper explores the extent to which the research-focussed experiential learning environment I designed for third-year undergraduate Education Studies students promoted student involvement, replicated the principles of communities of practice, and facilitated students' connections into and from their experiences as researchers.

\section{Methodological Discussion}

This research centred around the learning environment(s) that constituted my contact with the full student cohort $(\mathrm{n}=54)$ of third year Education Studies undergraduates in a small English university, through six three-hour generalised taught sessions on designing and pursuing a self-selected programme of research. In addition to the six taught sessions, comprising 18 hours of contact with each other and me, students also had access to five hours of specific, individual, supervision (with a range of tutors) over 
Post-print copy of article available at:

http://www.tandfonline.com/doi/pdf/10.1080/13562517.2016.1183621

Published online: 11 May 2016

the academic year. Within the taught sessions, learning activities were focussed on student involvement with my small scale study on how the cohort viewed research, and themselves as researchers. In common with a constructivist approach to learning and teaching, spaces for reflection and reflective discussion were built in to each activity.

In addition to a focus on our collaborative research, a Faculty Professor visited one session as guest speaker, sharing examples of their experience of data gathering/generation methods and ways of presenting analysed data, and the final session included an informal poster presentation activity, summarising all of our research studies. For this final session I modelled the visual presentation of our collaborative research by sharing my poster with students in advance, and through leading the 'showcase' of our research and inviting questions during the session. Also available to the cohort was the opportunity to attend the University Undergraduate Research Conference as delegates, and the option to participate in a short series of action learning sets, facilitated by me, to focus on experienced problems (Coghlan and Pedler, 2006) with students' individual research/dissertations.

Ethical approval for the research was granted by the University and, in the first taught session, the principles of ethical research practice were explored through discussion around the Research Study Information Sheet and the Informed Consent Form for this study. Students were invited to read the Information Sheet and to consider participating in the study. A choice not to participate (that is, not to contribute to data-generation around students' experiences as researchers) risked no predictable detriment. All students were able to participate in the classroom-based activities, which were centred on the emergent data from the study (those who had agreed to participate in the study had consented to their data being subject to collaborative analysis as part of 
Post-print copy of article available at:

http://www.tandfonline.com/doi/pdf/10.1080/13562517.2016.1183621

Published online: 11 May 2016

the informed consent procedure). The sampling strategy for the study was therefore opportunistic. 43 students chose to participate in the study (representing $\sim 79 \%$ of the cohort).

The study was framed within an interpretive paradigm and adopted a thematic analytical approach to qualitative data, designed to identify (a posteriori) emerging units of meaning (Wellington 2015). The research was not geared towards generalisation, instead it sought to explore this research issue (Bassey 1990), to identify potential opportunities for transferability and relatability (Lincoln and Guba 1985), and begin to consider implications for practice.

A detailed discussion of my positionality as both researcher and teacher is outside the scope of this paper. It is, however, a position which I recognise as 'multilayered and fluid' (Herr and Anderson 2014, 37), and with which I am familiar and experienced (Rand 2006, 2015).

\section{Data generation}

The study made use of three discrete data-generation opportunities:

(1) A Post-it note ${ }^{\mathrm{TM}}$ activity repeated twice, once in the second group session, and again in the fifth: "Thinking of yourself as a researcher, list 3 words which describe how you feel".

(2) Mid-module evaluation undertaken in the fourth group session - written open questions, based on an overarching focus: "As a novice researcher, what have you found useful?" 
Post-print copy of article available at:

http://www.tandfonline.com/doi/pdf/10.1080/13562517.2016.1183621

Published online: 11 May 2016

(3) Three action-learning set meetings, offered to students in addition to taught sessions, and made available on a self-selection basis.

Six different data-sets emerged from the study, two from the three-word activities, the mid-module review and one each from the three action learning sets.

\section{Three-words (Post-it note ${ }^{T M}$ activity)}

Data from the post-it note ${ }^{\mathrm{TM}}$ activities were used overtly within taught sessions to support authentic (student-led) data-analysis tasks, to prompt reflective discussion around analysing and presenting data, and to begin to explore (together) the implications of emergent findings.

\section{Mid-module evaluation}

The mid-module evaluation was completed, anonymously and in writing, in session four. The evaluation comprised five open questions (Table 1) focussed both on activities specific to the fourth session (the first after a six-week inter-semester break) and on students' general conception(s) of themselves as researchers (and the usefulness, or otherwise, of the taught sessions to support this). Specific activities in the fourth session had focussed on encouraging students to think about the methodological section of a dissertation. Within this session there was an interactive lecture-style activity which focussed on terminology common to research (for example: population, sample, piloting, trustworthiness, credibility, validity, reliability, reproducibility, generalisability). This activity ended with an informal formative assessment where 
Post-print copy of article available at:

http://www.tandfonline.com/doi/pdf/10.1080/13562517.2016.1183621

Published online: 11 May 2016

students were invited, individually, to review their own planned research activities using the terminology as a framework. After this individual activity students were invited to talk in small groups about their research, using the terms.

Feedback from all students was collated and shared with the students and the programme team, in accordance with the specific university policy on mid-module reviews. Data from students in the sample (43) were analysed (by me) for the purposes of this study; a summary was shared with students through the Virtual Learning Environment (VLE) in a written report and discussed verbally in a taught session. The raw dataset was also used to support a session activity with a particular focus on the identification of themes within a qualitative dataset.

[Table 1 near here]

\section{Action Learning Sets}

Five students took up the (self-selected) opportunity to participate in a series of three action-learning sets focussing on their research/dissertations. The small number of students comprising this dataset risked identification of participants within any general discussion of the data with the full cohort-group. These data were not therefore shared with the full cohort, although reference to emergent findings was recorded in my poster presentation.

I was situated deliberately as a facilitator and co-learner (non-teacher) within the sets. The first meeting was a highly structured and facilitated introduction to the principles of action learning, based on Langston's (2012) twenty-questions. The second was more loosely structured, and enabled each participant to outline a problem experienced with their research and to choose to answer questions generated by peers 
Post-print copy of article available at:

http://www.tandfonline.com/doi/pdf/10.1080/13562517.2016.1183621

Published online: 11 May 2016

(including myself) which they felt would best help them explore and respond to their problem [based on an adaptation of Hall's (2009) model where questions are written down and handed to the 'presenter' to choose from]. The third repeated this established structure and ended with a plenary (led by me) in which we discussed the impact of participating in an action learning set.

\section{Results and Discussion}

\section{Three words}

In sessions two and five, students were prompted: "Thinking of yourself as a researcher, list 3 words which describe how you feel”. In session two, a total of 125 words were listed by 43 participants. There were 51 separate words, of these nervous was listed most often: 21 times in total. (Nervous was also the most commonly listed first and second word). Of the 125 words listed, the top-three words were nervous ( 16\%), excited $(\sim 7 \%)$, and worried $(\sim 5 \%)$. Of the 51 separate words listed, approximately a third each were positive (for example excited, inquisitive, enthusiastic), negative (panic, underprepared, sick) and neutral or ambiguous (more in control, hungry).

In session five (four months later), a total of 96 words were listed by 38 participants. There were 54 separate words. The top-three words in this repeat activity were nervous $(\sim 9 \%)$, anxious $(\sim 7 \%)$, and worried $(\sim 6 \%)$. Nervous was the most common word (as before), listed nine times in total and representing approximately nine per cent of the responses. However, the most commonly listed first word was worried. In total nervous, anxious and worried, which can be considered synonymous, represented $\sim 22 \%$ of the total responses - a similar proportion to the combination of 
Post-print copy of article available at:

http://www.tandfonline.com/doi/pdf/10.1080/13562517.2016.1183621

Published online: 11 May 2016

nervous and worried in the first 'three-word' activity. Of the 54 separate words listed in this repeat activity there was a much clearer division of negative:positive orientation at nearly 2:1.

This deserves further scrutiny. At face-value these data intimate an adverse shift between sessions two and five. In the reality of the dissertation time-line this is the difference between the stages of literature review and data gathering/early analysis; feelings such as worry and anxiety are not uncommon to researchers at the stage of working with data. It is also important to acknowledge that participants' meanings were not triangulated. Terms used such as under-pressure, on-the-clock, fearful of final grade would be interesting to explore in more detail; similarly this activity was not designed to infer meaning, rather to elicit 'gut feelings' in terms of researcher-identities. Of note in this repeat activity, new, positive, words were also listed such as able, confident and content.

The 'three words' were indicative of affective states (as would be expected by the prompt: “...describe how you feel”). Ahmed's $(2014,11)$ warning that emotions can become 'sticky' is significant; treated uncritically, the impressions created by emotions could underpin students' moving toward or away from their identities as researchers. This activity then, is a useful one for those who support students in their transition(s) into researcher-hood, since '[A]ttention to emotions allows us to address the question of how subjects become invested in particular structures...' (Ahmed 2014, 12 original emphasis). The data are also consistent with other reports of social science undergraduate research; not only can the emotions associated with becoming a researcher be sticky, it is common also to feel 'stuck', to lack confidence and feel confused (Todd, Smith and Bannister 2006; Todd, Bannister and Clegg 2004). 
Post-print copy of article available at:

http://www.tandfonline.com/doi/pdf/10.1080/13562517.2016.1183621

Published online: 11 May 2016

Similarly, the combination of polarised terms in the repeat three-word activity also resonates with Silén and Uhlin's notion of 'chaos and cosmos' (2008).

\section{Mid-module evaluation.}

Themes that emerged from the responses to questions specifically about the fourth session were broadly as might be anticipated, for example reflecting on [gaps in] own progress and emerging [researcher] criticality. Noticeably, these were consistently mediated through talk:

Talking through different words and terms to include in the methodology. Clear [now] - wasn't so sure on this section before.

Talking to others about their research to see what methods their [sic] using, to understand their views on research and compare to mine.

Talking through the areas of research with someone else helped me to ensure the ideas for my research are strong enough.

This is significant, since talk did not emerge as central in the review of the literature of either STEM or SBES undergraduate students' experiences.

The significance of talk

Typically, there was little articulation of how talking is helpful to the developing researcher; where explanations were offered, they were generally indicative of the underpinning processes of reflection and criticality, such as clarifying or verifying ideas. Criticality is an essential skill for researchers. Significantly, most reference to talk was within peer groups (that is, as a community of beginning researchers), with far fewer examples of talking with those who might typically be considered knowledgeable 
Post-print copy of article available at:

http://www.tandfonline.com/doi/pdf/10.1080/13562517.2016.1183621

Published online: 11 May 2016

others such as tutors, supervisors, or academic librarians:

Collaborating with others in the group to discuss dissertations and at which stages we are at. This often helps us to clarify things that may have caused a problem later on.

Working through my ideas with a 'buddy' doing a similar topic allows in depth discussion and builds confidence with my ideas and research.

The uniqueness of talk within this study is two-fold. Firstly, as suggested by the literature review, community participation, social relationships and intellectual support were key to the success of this discovery-pedagogy (Thiry and Laursen 2011; Lopatto 2010; Shellito et al. 2001), however, there was no formal mentorship from more experienced others. Talk within the peer-group successfully effected a nuanced mode of apprenticing where, unlike in STEM when students purposefully join a mixedexperience community, the peers were similarly peripheral and actively creating their own [social science] beginning researchers community of practice. Secondly, if, as Wenger (1998) argues, meanings result from the interaction between personal/social participation and reification (a conversion from, and conversation about, abstract to concrete), talking can also be considered as capable of mediating meaning(s) in social science undergraduate research.

\section{Action learning sets}

As might be anticipated in a process predicated on critical colleagueship (Lord 1994), where small groups of people or a 'set' of colleagues with diverse perspectives come 
Post-print copy of article available at:

http://www.tandfonline.com/doi/pdf/10.1080/13562517.2016.1183621

Published online: 11 May 2016

together formally to help each other understand 'experienced problems' through a process of reflective questioning (Coghlan and Pedler 2006; McGill and Brockbank 2004; McGill and Beaty 2001), talk also emerged as significant from the action learning set data. Unlike the class-based activities, where talk was effectively optional, those participating in the action learning sets had purposefully chosen to engage in researchfocussed conversation(s). Notably, across the three sets, the focus of the talk shifted from setting practical targets in the first set, through recognising emotional responses to experience(s) in the second, to re-framing experiences in the final set.

In the second set, familiar reports of being scared and feeling stuck emerged in the dialogue. From the, earlier, three-word data I had a sense that such affective states might result in students moving away from research or their researcher-identities; the context of the action learning set however, enabled a deeper participant-exploration, which was unavailable in the three-word activity:

Literature review and methodology are under control but I'm scared about the research... worried it's too small...worried it found what I want it [expect] to find...daunting...

I enjoyed the research associated with the literature review, I went very wide; I have set myself a word limit but have already exceeded this...I found so much...I'm getting bogged down...I want to move on, but don't seem to be able to...

I have sulked with my research problem because of feedback on another module. I don't know how to use the feedback constructively. I've attempted various sections of the dissertation, none is fully completed... I don't know how to move on.

As a result, talk enabled a deliberate towardness focussed on developing both research 
Post-print copy of article available at:

http://www.tandfonline.com/doi/pdf/10.1080/13562517.2016.1183621

Published online: 11 May 2016

and researcher-identities:

I'm going to find people I can be accountable to, and who won't be nice to me! I'll share my targets/timescales... [and] negotiate a date with my supervisor for submission of a draft and formative feedback.

I need to accept that I have to stop [reading the literature]...move on the research, then reflect later.

I need to get over it [laughs]...revisit the feedback and use it to help me finish my literature review.

The most powerful talk occurred in the final action learning set, both in terms of affective states being 'othered' (Ahmed 2014):

You do get scared, but this is a chance for you to make a difference... [and] you don't want to disappoint others [student is referring both to their supervisor and their own research participants]

Now that I have some data it's far more interesting... If I was going to do it again, I'd get it [the literature review] done earlier. I was worried about putting people out...

and in terms of participants recognising their own investedness and movement towards (Ahmed 2014) their researcher-identities:

Our first actions were very practical and target-oriented; the second focus on "leaving something behind" or "letting go", we are more adaptive and more protective of what we've done. At first we spoke about things we think we believe, in the second set we spoke about things that are actually happening.

People get that scared, they don't do things. I'm like that. Doing this helps me, and I'm happy to help others; it's not judgemental. It was helpful with self-reflection, just saying things out loud orders things. It was helpful to verbalise "this is what I feel" rather than "just feeling it". The discussion is like "dissertation therapy". 
Post-print copy of article available at:

http://www.tandfonline.com/doi/pdf/10.1080/13562517.2016.1183621

Published online: 11 May 2016

(Composite quotations of statements made by participants in conversation in the final set)

Talk in this context then appears to support a more powerful improvement (a strong improvement that has significant potential to benefit participants).

In common with the talk in the taught sessions, students who participated in the action learning sets were similarly peripheral within the beginning researchers community. Notably the action learning sets presented the opportunity for students to belong to another community of practice [Wenger (1998) argues that we belong to several communities of practice at any given time; each rarely coming into explicit focus] and the apprenticeship from this community of practice enabled students to shift from the reactive 'interiority' of emotions (Ahmed 2014, 8) [reported in the three-words activity] to a responsive, meaning-making, exteriority that enabled students to move towards their research and researcher-identities. As a result, talk within action learning sets more powerfully operationalised student involvement (Astin 1999) and located students' 'connected learning' (Taylor and Wilding 2009) firmly in the mode of 'being done with' rather than 'being done to' (Taylor and Wilding 2009, 3).

\section{Concluding comments}

This study developed as a response to feedback from students progressing into their third year of full-time undergraduate study. I was interested to learn whether the lived experience of participating in a research study could support students to develop a more nuanced identity, as both student and also researcher. I set out with an intention to model the process of undertaking a small-scale research project with students in the 
Post-print copy of article available at:

http://www.tandfonline.com/doi/pdf/10.1080/13562517.2016.1183621

Published online: 11 May 2016

context of six taught sessions to support them to design and pursue a self-selected programme of original research associated with their third-year dissertation, thereby providing a research-focussed experiential learning opportunity. My outline research question was how does acting as a research participant impact undergraduate students' experience as researchers?

The extant literature base, although sparse for undergraduate research in the social sciences, suggests that participatory pedagogies and scholarship-driven authentic learning experiences can create structure(s) for beginning researchers that enable them to, peripherally, enter legitimate communities of practice (Thiry and Laursen 2011; Taylor and Wilding 2009; Wenger 1998). This active participation of students, imbued in research, can facilitate Astin's (1999) notion of student involvement and result in 'connected learning' (Taylor and Wilding 2009).

The literature suggests the role of mentoring is common in STEM subjects, and supports undergraduate research students in an apprenticing, laboratory-based, model of learning (Thiry and Laursen 2011; Lopatto 2010; Shellito et al. 2001). STEM mentors are typically considered as knowledgeable others, that is (more) experienced postgraduate students. This model is not readily replicated in SBES research, and undergraduates report experiencing challenges including: feelings of fear and anxiety, intellectual confusion, and feeling 'stuck' at the boundaries of new qualitative shifts in understanding, (Todd, Smith and Bannister 2006; Todd, Bannister and Clegg 2004). This paper explores the extent to which the research-focussed experiential learning environment I designed promoted student involvement, replicated the principles of communities of practice, and enabled social science students to exploit both their research experiences and their experiences as researchers. 
Post-print copy of article available at:

http://www.tandfonline.com/doi/pdf/10.1080/13562517.2016.1183621

Published online: 11 May 2016

In a "three-word" activity, I found that students reported 'sticky' feelings (Ahmed 2014), or emotionally-saturated responses when asked to consider themselves as researchers, in common with other reports of undergraduate social science research (Todd, Smith and Bannister 2006; Todd, Bannister and Clegg 2004). This interiority (Ahmed 2014) can result in students intentionally moving toward, or away from, the object of the emotion, and for a beginning researcher, moving away from research or researcher-identity is problematic.

In a mid-module review activity, talk emerged as a reflective pedagogic strategy that was significant in two ways: it was successfully enabling apprenticeship, and it was mediating meaning. Although replicative of the successes of STEM undergraduate research apprenticeship (Thiry and Laursen 2011; Lopatto 2010; Shellito et al. 2001), this is a distinct mode of apprenticeship, one in which similarly peripheral beginning researchers engage with, and create, communities of practice.

Bespoke opportunities for similarly peripheral beginning researchers to explore the meanings behind their feelings, through the critical colleagueship (Lord 1994) of a series of action learning set meetings, appeared to ameliorate 'awayness'. Whilst feelings of 'stuckness' and fear were experienced by students who participated in the sets, critically reflective peer-dialogue enabled a deliberate 'towardness', focussed on developing both research and also researcher-identities. Although few in number, the action learning sets were transformative. All students who participated were able to shift from the interiority of emotions to the responsiveness of affect (Ahmed 2014), and to re-frame their emotional unsettlement through talk.

This small-scale research created opportunities to learn with and from each other by drawing on practical experience(s), not simply by inviting critical colleagueship of 
Post-print copy of article available at:

http://www.tandfonline.com/doi/pdf/10.1080/13562517.2016.1183621

Published online: 11 May 2016

students' individual experiences but also through creating a shared practical experience of participating in my research project. Accepting the necessity for wider discussion around my positionality (which will be published separately), this way of working proved interesting and was positively experienced by students. As such, I will continue to use it, and it may be of interest to others who teach in Higher Education.

In conclusion, this study fills gaps in the literature around undergraduate research in the social sciences. The implications of the issues explored within this study are threefold. First, the mode of apprenticeship and mediating meaning in undergraduate social science research is distinct because it can be realised through beginning researchers communities of practice, in which all members are similarly peripheral. Second, talk as reflective pedagogy can make connections within and between research experiences and into and from experiences as researchers accessible to students, and exploitable by them. Third, critically reflective talk within beginning researchers communities of practice can support students to reframe emotional unsettlement, and enable Ahmed's (2014) notion of 'towardness'. Talk can powerfully improve undergraduate social science research students' experiences.

\section{Acknowledgements}

The author would like to thank the participating students, particularly for being prepared to share openly and honestly their personal experiences as researchers, and Professor Matthew Clarke for his helpful comments and suggestions on the draft paper. Similarly, the author is grateful to the journal referees for constructive and developmental feedback. 
Post-print copy of article available at:

http://www.tandfonline.com/doi/pdf/10.1080/13562517.2016.1183621

Published online: 11 May 2016

References

Ahmed, S. 2014. The Cultural Politics of Emotion. $2^{\text {nd }}$ ed. Edinburgh: Edinburgh University Press.

Argyris, C. 1976. "Single-Loop and Double-Loop Models in Research on Decision Making.” Administrative Science Quarterly 21 (3): 363-375.

Ashwin, P., D. Boud, K. Coate, F. Hallett, E. Keane, K.L. Krause, B Leibowitz et al. 2015. Reflective Teaching in Higher Education. London: Bloomsbury.

Astin, A. 1999. "Student Involvement: A Developmental Theory for Higher Education." Journal of College Student Development 40 (5): 518-529.

Balster, N., C. Pfund, R. Rediske, and J. Brancha. 2010. "Entering Research: A Course That Creates Community and Structure for Beginning Undergraduate Researchers in the STEM Disciplines." CBE-Life Sciences Education 9: 108118.

Barnett, R. 2000. "Supercomplexity and the curriculum.” Studies in Higher Education 25 (3): 255-265.

Bassey, M. 1990. "On the Nature of Research in Education (Part I.)" Research Intelligence 36 (Summer): 35-38.

Bauer, K.W., and J.S. Bennett. 2003. "Alumni Perceptions Used to assess Undergraduate Research Experience." The Journal of Higher Education 74 (2): 210-230.

Clarke, M. 2010. “Doing 'Identity Work' in Teacher Education: The Case of a UAE Teacher." In The World Yearbook of Education 2010. Education and the Arab 'World': Political Projects, Struggles, and Geometries of Power, edited by A.E. Mazawi and R.G. Sultana, 145-162. New York: Routledge.

Coghlan, D., and M. Pedler. 2006. “Action learning dissertations: structure, supervision and examination." Action Learning Research and Practice 3 (2): 127-139.

Dilworth, R.L. and V.J. Willis. 2003. Action Learning: Images and Pathways. Florida: Krieger Publishing Company.

Hall, I. 2009. "New ways of introducing Action Learning." Paper presented at IFAL Annual Conference, Glasgow, October. 
Post-print copy of article available at:

http://www.tandfonline.com/doi/pdf/10.1080/13562517.2016.1183621

Published online: 11 May 2016

Hathaway, R.S., B. Nagda, and S. Gregerman. 2002. "The Relationship of Undergraduate Research participation to graduate professional education pursuit: An empirical study." Undergraduate Research and Postgraduate Education 43 (5): 1-17.

Healey, M., and A. Jenkins. 2009a. Developing undergraduate research and inquiry. HEA. Available online at: https://www.heacademy.ac.uk/node/3146

Healey, M., and A. Jenkins. 2009b "International Perspectives on Strategies to Support faculty Who Teach Students Via Research and Inquiry." CUR Quarterly 35(3): $31-37$.

Herr, K., and G.L. Anderson. 2014. The Action Research Dissertation - A Guide for students and faculty. $2^{\text {nd }}$ ed. London: Sage.

Ishiyama, J. 2002. "Does early participation in undergraduate research benefit social science and humanities students?" College Student Journal 36 (3): 380 - 386. Available online at: http://reserachgate.net/publication/237386612

Kilburn, D., M. Nind, and R. Wiles. 2014. "Learning as Researchers and Teachers: The Development of a Pedagogical Culture for Social Science Research Methods?" British Journal of Educational Studies 62 (2): 191-207.

Kinkead, J. 2003. "Learning Through Inquiry: An Overview of Undergraduate Research." New Directions for Teaching and Learning 93: 5-18.

Langston, D. 2012. An Introduction to Action Learning. Available online at: http://www.youtube.com/watch? feature=player embedded\&v=LbyuL1deMWQ

Lincoln, Y., and E. Guba. 1985. Naturalistic Inquiry. London: Sage.

Linn, M.C., E. Palmer, A. Baranger, E. Gerard, and E. Stone. 2015. "Undergraduate research experiences: impacts and opportunities.” Science 347 (6222): 627.

Lopatto, D. 2004. "Survey of Undergraduate Research Experiences (SURE): First Findings." Cell Biology Education 3 (Winter): 270-277.

Lopatto, D. 2007. “Undergraduate Research Experiences Support Science Career Decisions and Active Learning." CBE-Life Sciences Education 6 (Winter): 297306.

Lopatto, D. 2010 “Undergraduate Research as a High-Impact Student Experience.” Peer Review 12 (2): 27-30. 
Post-print copy of article available at:

http://www.tandfonline.com/doi/pdf/10.1080/13562517.2016.1183621

Published online: 11 May 2016

Lord, B. 1994. "Teachers' professional development: Critical colleagueship and the role of professional communities." In: The Future of Education: Perspectives on national standards in education, edited by N. Cobb, 175-204 New York: College Board.

McGill, I. and L. Beaty. 2001. Action Learning - a guide for professional, management and educational development. Revised 2nd ed. Abingdon: RoutledgeFalmer.

McGill. I., and A. Brockbank. 2004. The Action Learning Handbook. Powerful techniques for education, professional development \& training. Abingdon: RoutledgeFalmer.

Rand. J. 2015. Dimensions of knowing: a conceptual alternative to an unhelpful polarity between knowledge and skill. Research in Post-Compulsory Education, 20 (2): 140-158. DOI: 10.1080/13596748.2015.1030245

Rand, J. 2006. Mini-ethnography: a multi-method approach in an ESOL IT class. Reflecting education 2 (1): 85-102. http://reflectingeducation.net/

Russell, S.H., M.P. Hancock, and J. McCullough. 2007. "Benefits of Undergraduate Research Experiences.” Science 316: 548-9.

Sabatini, D.A. .1997. "Teaching and Research Synergism: the Undergraduate Research Experience." Journal of professional issues in engineering education and practice 123 (3): 98-102.

Shellito, C., K. Shea, G. Wiessman, A. Mueller-Solger, and W. Davis. 2001. "Successful Mentoring of Undergraduate Researchers. Tips for Creating Positive Student Research Experiences.” Journal of College Science Teaching 30 (7): 460-464.

Silén, C., and L. Uhlin. 2008. "Self-directed learning - a learning issue for students and faculty!" Teaching in Higher Education 13 (4): 461-475.

Spronken-Smith, R., R. Walker, B. O’Steen, J. Batchelor, H. Matthews, and T. Angelo. 2008 Inquiry-based Learning Report. Prepared for New Zealand Ministry of Education. Available online at: https://akoaotearoa.ac.nz/project/inquiry-basedlearning/resources/books/inquiry-based-learning-report

Tapp, J. 2015. "Framing the curriculum for participation: a Bernsteinian perspective on academic literacies." Teaching in Higher Education 20 (7): 711-722. 
Post-print copy of article available at:

http://www.tandfonline.com/doi/pdf/10.1080/13562517.2016.1183621

Published online: 11 May 2016

Taylor, P., and D. Wilding. 2009. Rethinking the values of higher education - the student as collaborator and producer? Undergraduate research as a case study. QAA. Available online at: http://www.qaa.ac.uk/en/Publications/Documents/Rethinking-the-values-ofhigher-education---students-as-change-agents.pdf

Thiry, H. and S.L. Laursen. 2011. "The role of Student-Adviser Interactions in Apprenticing Undergraduate Researchers into a Scientific Community of Practice." Journal of Science Education Technology 20 (6): 771-784.

Todd, M., P. Banister, and S. Clegg. 2004. "Independent inquiry and the undergraduate dissertation: perceptions and experiences of final-year social science students." Assessment \& Evaluation in Higher Education 29 (3): 335-355.

Todd, M.J., K. Smith, and P. Bannister. 2006. "Supervising a Social Science Undergraduate Dissertation: Staff Experiences and Perceptions." Teaching in Higher Education 11 (2): 161-173.

Wellington, J. 2015. Educational Research. Contemporary Issues and Practical Approaches. $2^{\text {nd }}$ ed. London: Bloomsbury.

Wenger, E. 1998. Communities of Practice. Learning, Meaning and Identity. Cambridge: Cambridge University Press.

Zepke, N. 2014. "Student engagement research in higher education: Questioning an academic orthodoxy." Teaching in Higher Education 19 (6): 697-708. 
Post-print copy of article available at:

http://www.tandfonline.com/doi/pdf/10.1080/13562517.2016.1183621

Published online: 11 May 2016

Table 1: Mid-module evaluation questions

1. What have you learned about being a researcher from today's session?

2. What specific activities have you found useful TODAY; how did they help you?

3. Thinking of yourself as a novice researcher, what other activities have you found useful (outside of today's session); how did they help you?

4. What are your next steps in your current research project?

5. What activities do you find BEST help you to understand, and apply, the principles of research? Prioritise three. 